\title{
SMOKING-RELATED BEHAVIOURS OF PREGNANT WOMEN DEPENDING ON THEIR PLACE OF RESIDENCE
}

\author{
Magdalena Zawadzka', Andrzej Buczyński ${ }^{1}$, Włodzimierz Stelmach ${ }^{2}$, Alina Kowalska ${ }^{2}$, Gabriela Henrykowska ${ }^{1}$ \\ 'Department of Epidemiology and Public Health, Medical University of Łodź, Łodź, Poland \\ 2Department of Social Medicine, Medical University of Łodź, Łodź, Poland
}

\section{SUMMARY}

Objectives: Smoking is a commonly recognized risk factor of civilization diseases. Despite many educational programmes concerning harmful effects of tobacco smoking, this habit is still very popular. Particularly alarming is a high percentage of pregnant women who smoke.

Methods: The aim of the study was to analyse the prevalence of smoking among pregnant women depending on their place of residence. The research was conducted in randomly selected 30 outpatient clinics for women in Łodź and 16 outpatient clinics in rural communes of the Łodź province. The epidemiological analysis included 400 women. Collected data were processed statistically using the descriptive methods and statistical inference.

Results: It has been demonstrated that smoking in the past was more popular among city residents than countryside residents (58.2\% and $47.9 \%$, respectively). Women living in the city smoked almost three times more frequently during the whole pregnancy than the respondents from the countryside ( $13.4 \%$ and $4.3 \%$, respectively). Furthermore, every fifth respondent living in the urban area $(f=0.21)$ smoked over 10 cigarettes a day, and every fourth respondent from rural communes $(f=0.24)$ smoked from 5 to 10 cigarettes a day. However, in the month preceding the research, pregnant women from rural areas smoked slightly more frequently as compared to the subjects from the city. In the group of pregnant women who smoked in the past or who smoke at present, regardless from their place of residence, every other woman did not breastfeed her baby. $6.1 \%$ of city residents and $4.3 \%$ of countryside residents declared that they smoked during the breastfeeding period.

Conclusions: Within the analysed population the influence of place of residence on the prevalence of active smoking, number of smoked cigarettes and giving up smoking during pregnancy and breastfeeding period has been evidenced.

Key words: smoking, passive smoking, pregnant women, city, countryside

Address for correspondence: M. Zawadzka, Department of Epidemiology and Public Health, Medical University of Łodź, ul. Żeligowskiego 7/9, 90-752 Łódź, Poland. E-mail: magdalena.zawadzka@umed.lodz.pl

https://doi.org/10.21101/cejph.a4564

\section{INTRODUCTION}

Consequences of tobacco smoking have been studied thoroughly. Epidemiological research indicates that smoking is the single most important and avoidable reason of death in the world.

The Global Adult Tobacco Survey (GATS) data for the general population in Poland indicate that $21 \%$ of adult women smoke tobacco every day (1). According to the World Health Organization (WHO), the percentage of women smokers in 2002-2005 was $25.6 \%$; it was two percentage points higher as compared to 1994-2001 (2).

Smoking tobacco is a very serious health problem among young women. Approximately $1 / 3$ of women who smoke continue smoking during pregnancy. Smoking generates many health risks. The most alarming ones include those concerning infants, babies and small children, who are exposed to toxic substances contained in tobacco smoke. Consequences are very serious when a mother smokes during pregnancy as well as when she stays in the environment where tobacco smoke is present (3). Results from the WHO research show that $60.0 \%$ of pregnant women in Poland are exposed to inhalation of tobacco smoke at work or at home (4). The most frequent consequences of smoking during pregnancy include premature birth, limited growth of the foetus in the uterus, low birth body weight, lower body height of infants, hypoxia, respiratory and neural diseases, sudden infant death syndrome, obesity, allergy, hypertension, and sometimes even tumours (5). In the opinion of the WHO General Director, the probability of death due to tobacco-related diseases risked by children in the future is nearly 300 million out of the present population at the developmental age. Therefore, he proposes to supplement the Convention of the Rights of the Child with: "Necessity of protecting children from tobacco" (6). It is believed that children exposed to tobacco smoke during the foetal stage and after birth have a higher disease incidence and mortality rate up to 5 years of age (5). It is estimated that if all mothers gave up smoking during pregnancy, the mortality rate among children would be reduced by $10 \%$ (7). Therefore, it is important to conduct preventive activities concerning the health problems described above by eliminating tobacco smoke, which is harmful to children's development, as early as from the first days after the conception. Despite so many 
related hazards, smoking is still frequent among pregnant women. Therefore, anti-nicotine education should include young women and should be continued by outpatient clinics for pregnant women.

\section{MATERIALS AND METHODS}

The analysis of the prevalence of tobacco smoking among pregnant women depending on the place of residence has been performed.

The research was conducted from January to May 2011 in patients of randomly selected 30 outpatient clinics for women in Łodź and 16 outpatient clinics from rural areas of the Lodź province. Patients waiting for an appointment were asked to fill in a questionnaire including 33 questions concerning tobacco smoking. During the survey period, 400 women came to the clinics, out of which 336 women came to undergo preventive tests related to the course of their pregnancy and 64 women came to have their pregnancies confirmed.

The collected empirical data were processed statistically, using descriptive methods and statistical inference. In order to compare the frequency of individual variations of properties in the examined groups and subgroups, the $\chi^{2}$ independence test was used.

\section{RESULTS}

Out of 400 respondents participating in the research, 256 $(64.0 \%)$ lived in the city and $144(36.0 \%)$ lived in the countryside. In the analysed group, 336 women visited clinics for control examination of already confirmed pregnancy and 64 women came in order to confirm the pregnancy. $65.5 \%$ of the pregnant women lived in urban areas and $34.5 \%$ of them lived in rural areas. In the group of patients who came to confirm their pregnancy (probably pregnant) these percentages were $56.3 \%$ and $43.7 \%$, respectively (Fig. 1).

The analysis of the prevalence of smoking in the past, i.e. six months prior to the survey, did not show any statistically significant differences between the residents of cities and rural areas (Fig. 2).

A slightly lower percentage of women living in the city smoked cigarettes in the last month before the survey compared with re-

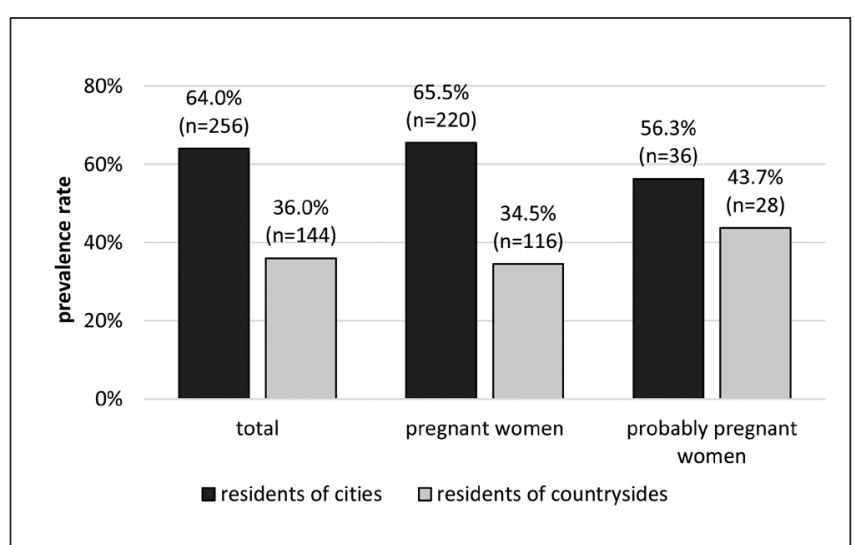

Fig. 1. Residents structure according to the place of residence $(N=400)$.

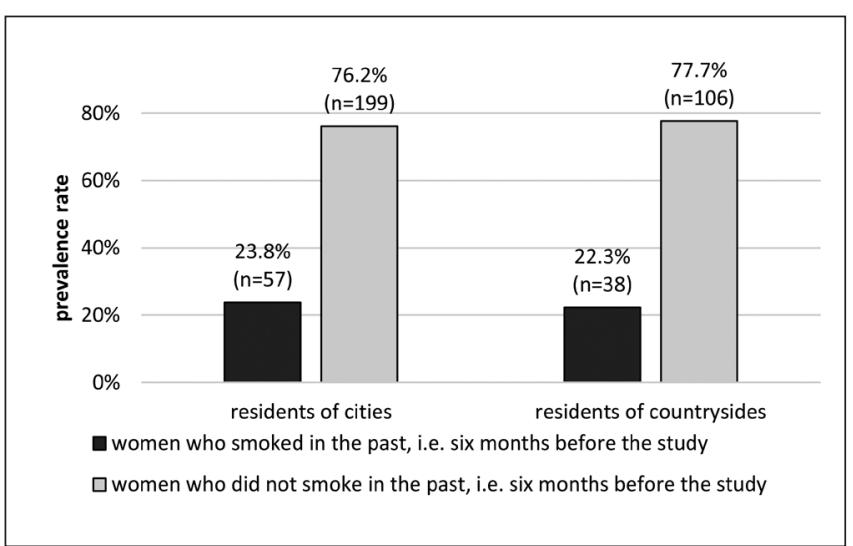

Fig. 2. Respondents'behaviour regarding smoking in the past, i.e. six months before the survey, depending on the place of residence $(N=400)$.

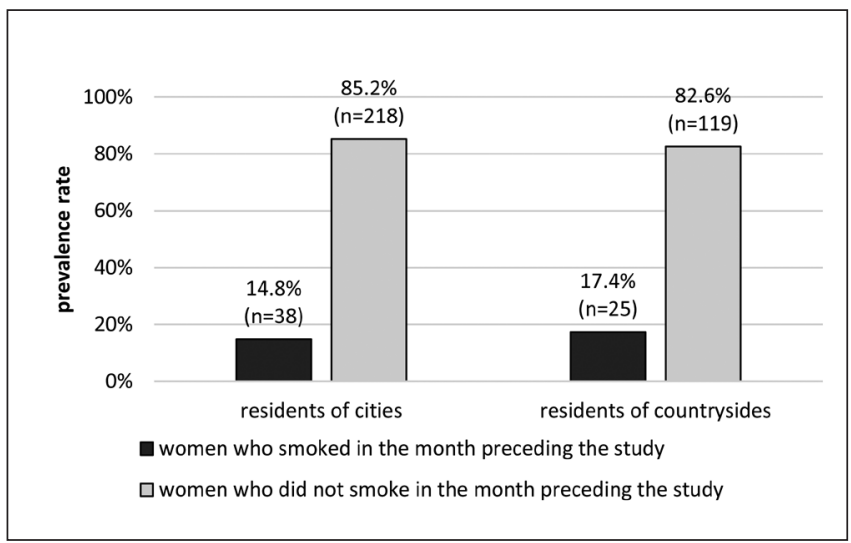

Fig. 3. Respondents' behaviour regarding smoking in the last month before the survey, depending on the place of residence $(N=400)$.

spondents in rural areas, $14.8 \%$ and $17.4 \%$, respectively (Fig. 3).

A statistically significant difference was observed in the popularity of smoking in the past depending on the place of residence $\left(\chi^{2}=3.932 ; \mathrm{p}<0.05\right)$. Significantly less respondents from the urban areas $(58.2 \% ; \mathrm{n}=149)$ declared that they had smoked actively in the past than those living in the countryside did $(47.9 \% ; n=69)$. Only every fourth woman living in the city $(41.8 \% ; n=107)$ and every fifth woman living in the countryside $(52.1 \% ; \mathrm{n}=75)$ never smoked cigarettes (Fig. 4).

Alarming is the phenomenon of active smoking among pregnant women. Every fifth respondent living in the urban area $(\mathrm{f}=0.21)$ smokes more than 10 cigarettes a day and every fourth respondent from the rural areas $(\mathrm{f}=0.24)$ smokes $5-10$ cigarettes a day, causing harm not only to herself but also to her unborn baby. Every third woman, regardless from her place of residence, smokes 3-4 cigarettes a day. Furthermore, almost every fifth city resident $(f=0.18)$ and every fourth countryside resident $(f=0.24)$ smokes up to 2 cigarettes a day (Fig. 5).

A higher percentage of respondents living in the urban areas smoked during their pregnancy. Women living in the city smoked during the whole pregnancy nearly three times more frequently than the respondents from the countryside, $13.4 \%$ and $4.3 \%$, respectively. Furthermore, $17.4 \%$ of the respondents from the urban areas and $14.9 \%$ of those from the rural areas declared that they had inhaled tobacco smoke for a part of their pregnancy. Higher 


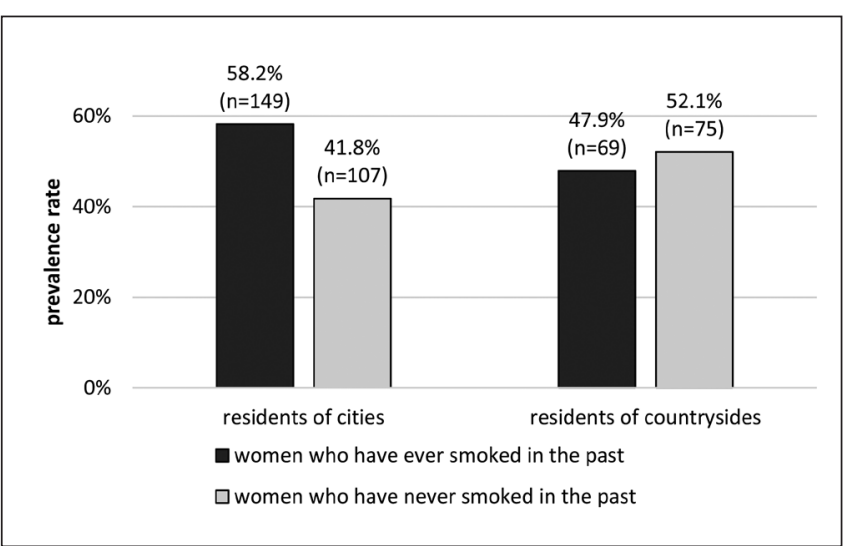

Fig. 4. Respondents'behaviour regarding ever smoking in the past, depending on the place of residence $(N=400)$.

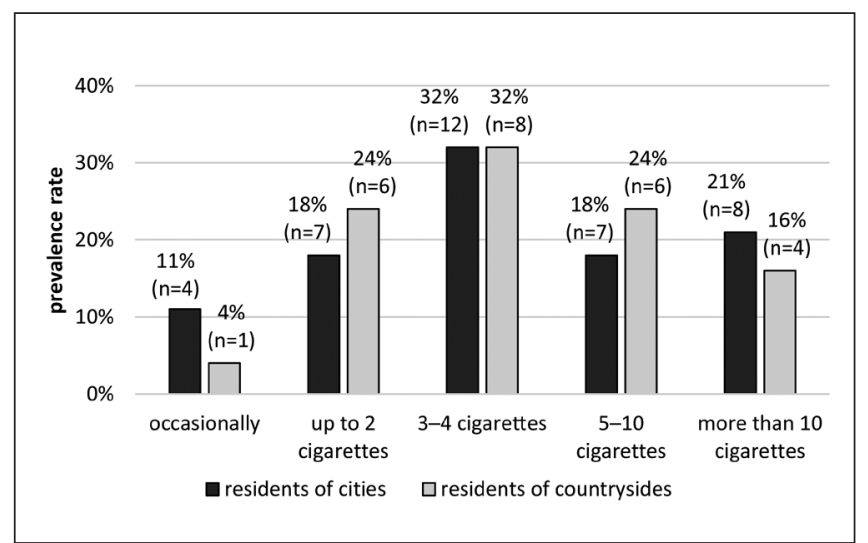

Fig. 5. Number of cigarettes smoked by pregnant women, depending on the place of residence $(N=63)$.

percentage of respondents from the rural areas $(81.2 \%)$ as compared to the city residents (69.2\%) gave up smoking after having their pregnancy confirmed, showing responsibility for their own health and for the health of their baby (Fig. 6).

A small percentage of the city residents $(6.1 \%)$ as well as the countryside residents $(4.3 \%)$ continued smoking cigarettes during breast-feeding. The respondents living in the rural areas showed great determination and strong will to fight and did not return to smoking during the breastfeeding period more frequently (43.5\%) as compared to the respondents living in the urban areas (37.5\%) (Fig. 7).

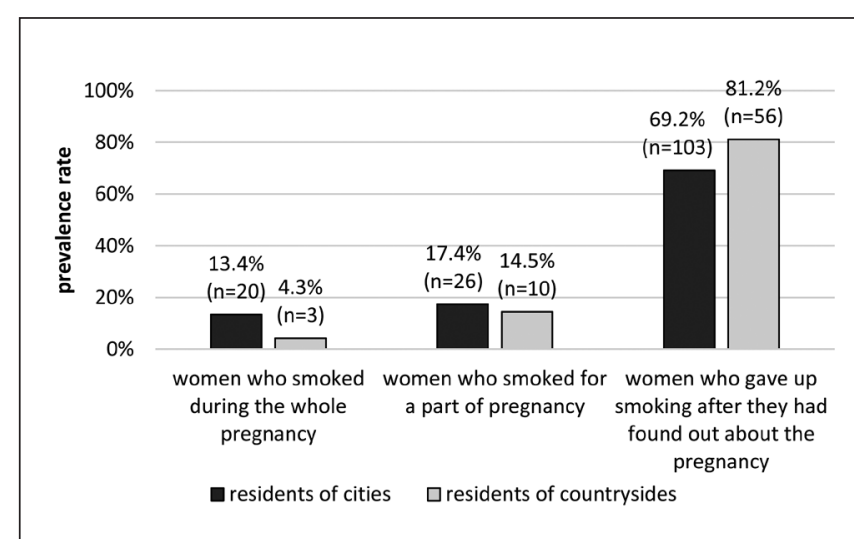

Fig. 6. Respondents who have ever smoked cigarettes during pregnancy, depending on the place of residence $(N=218)$.

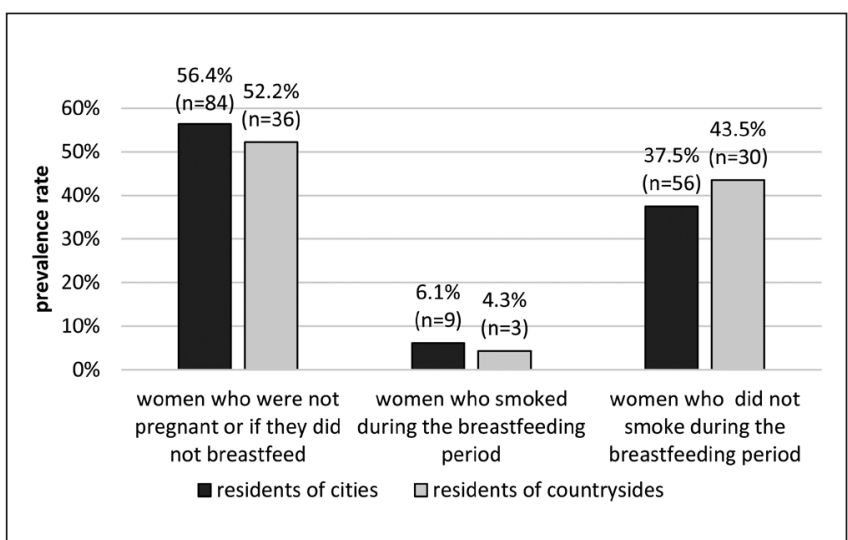

Fig. 7. Behaviour of respondents who have ever smoked, associated with cigarette smoking during breastfeeding, depending on the place of residence $(N=218)$.

\section{DISCUSSION}

Smoking tobacco is still a serious problem for services responsible for health of the society. Despite many anti-smoking campaigns informing about the harmfulness of smoking and encouraging people to stop smoking, the percentage of smokers is still high. Experiences from the recent years have shown that to fight the smoking epidemics is very difficult and it is a world-wide problem. In the survey by Kaleta et al., only $52.0 \%$ of women declared that they had never smoked and $28.0 \%$ of them smoked at the time of the survey (8). In this work, the authors observed that the residents of the rural areas actively inhaled tobacco smoke more frequently compared to the respondents living in the urban areas, $52.1 \%$ and $41.8 \%$, respectively.

Smoking tobacco is an addiction with negative consequences, which are constantly communicated to the society. Despite the fact, some pregnant women, regardless of the hazards, smoke cigarettes, exposing themselves and their babies to the risks. According to the data from the European Centre of WHO, the largest percentage of pregnant women smokers live in Greece and Ireland (over 50\%) and the smallest one in the Czech Republic (approximately 5\%) and Sweden (approximately 13\%) (9). In the USA, approximately $21 \%$ of all pregnant women smoke, $35.0 \%$ out of which are indigenous Americans, $24.0 \%$ are white, $22.0 \%$ are African Americans, and 11.0\% are Asians (10). Similar results were obtained in the research by Brodsky et al., where the mean frequency of smoking among pregnant women was $20.4 \%, 9.5 \%$ of women gave up smoking after having their pregnancy confirmed, $24.6 \%$ reduced the number of smoked cigarettes, $26.8 \%$ smoked as before, and $33.5 \%$ increased the number of smoked cigarettes (11). The research conducted in Poland showed that $69.4 \%$ of pregnant women are exposed to passive inhalation of tobacco smoke and $20.8 \%$ of pregnant women smoke tobacco actively $(12,13)$. In Sweden, 8.0\% of pregnant women smoke during the early stage of their pregnancy (from 6th to 12th week of pregnancy) and $7.0 \%$ of them smoke in the advanced stage of pregnancy (from 31st to 34th week of pregnancy) (9). Unfortunately, according to other sources, $23.0 \%$ of women smoke in the 1st trimester and $18.0 \%$ of women smoke in the 3 rd trimester (14). Many scientific centres in the world conducted research on giving up smoking tobacco during pregnancy. Japan is the country where the greatest number of women give up smoking during pregnancy. 
This is confirmed by the research of Suzuki et al. and Kaneita et al., where the percentage of women who gave up smoking was $69.7 \%$ and $61.9 \%$, respectively $(15,16)$. On the other hand, in Israel 47.3\%, in Sweden 47\%, in France 41.6\%, in Spain 40.3\%, in Australia $40.0 \%$, and in the USA $39.0 \%$ of women give up smoking during pregnancy (17-22). According to Connor and Mc Intyre, Canada belongs to the countries where the percentage of pregnant women giving up smoking is low (8.3\%) (23). The limitation of the use of addictive substances during pregnancy may be related to the fact that pregnancy was unplanned, but it may also reflect the awareness of necessity to limit the exposure for the sake of the child. On the other hand, in France 22.0\%, in Denmark 30.0\%, in Russia 36.0\%, in Switzerland 10.0\%, in Portugal $56.0 \%$, and in Japan $27.0 \%$ of women smoke cigarettes actively during their pregnancy $(19,24-28)$. In the research by Al-Sahab et al. conducted in 2005-2006 among Canadian women, $22.0 \%$ of respondents declared that they had smoked before pregnancy and $16.5 \%$ after the childbirth. $10.5 \%$ of respondents actively exposed their babies to the inhalation of tobacco smoke, including $6.9 \%$ who did it every day, and 3.6\% occasionally (29). In Turkey, every fourth woman fails to stop smoking during her pregnancy. 3/4 of them are pregnant women smoking every day (30).

The analysis of the survey results concerning the frequency and type of exposure to tobacco smoke in Poland and Mexico indicates that the frequency of smoking before pregnancy among Polish and Mexican women is similar, $25.0 \%$ and $26.8 \%$, respectively. $19.5 \%$ of Polish women continued smoking during the whole pregnancy, this percentage was lower among Mexican women (11.1\%). The frequency of giving up smoking after becoming pregnant in the Polish population was $19.5 \%$ and in the Mexican population $55.5 \%$ (31).

In the research by Borkowski and Mielniczuk the analysis included approximately 20,000 questionnaires filled in by pregnant women in various hospitals in Poland. $16.7 \%$ of women declared that they had smoked at some time in their lives; $14.4 \%$ that they had smoked during the last year before pregnancy; $27.0 \%$ of women gave up smoking at the beginning of their pregnancy; $36.4 \%$ of women gave up or limited smoking during pregnancy; and as many as $36.5 \%$ of women smoked as before (32). In the present study, we observed a higher percentage of women smoking in the past, $69.2 \%$ living in the city and $81.2 \%$ living in the countryside, who gave up smoking after having their pregnancy confirmed. However, the respondents who continued smoking for a part of pregnancy were $17.4 \%$ of women living in the city and $14.5 \%$ of women living in the countryside. Alarming is the fact that the city residents smoked cigarettes for the whole pregnancy three times more frequently than the respondents from the rural areas did. The number of pregnant women smoking cigarettes coupled with the adverse effects of smoking on the development of a new-born baby indicates the social nature of this problem.

In their clinical and control research conducted in 1994-1997, Bodzek et al. found that $39.5 \%$ of pregnant women smoked before pregnancy. In the group of mothers who smoked at some time in their lives, $88.9 \%$ smoked during the month preceding the conception. The information about pregnancy resulted in giving up smoking only in $21.5 \%$ of women smoking tobacco (14). In the research conducted among 100 women who came to hospital to give birth to a child, chronic nicotine addiction with the average period of smoking of 6.8 years was found in $34 \%$ of them. This group included $17.6 \%$ of women who gave up smoking after the confirmation of the pregnancy; $82.4 \%$ of women smoked during the whole pregnancy reducing the number of cigarettes a day. It was observed that the habit of smoking was common between younger pregnant women (33). In the present study the authors also observed the influence of the information about pregnancy on giving up smoking. Among the pregnant women, 23.8\% of respondents living in the urban areas and $22.3 \%$ of those living in the rural areas smoked during the last six months preceding the research; on the other hand, the percentages of those smoking during the last month before the research were lower (14.8\% and $17.4 \%$, respectively).

In the research conducted among 659 mothers living in rural communes and city areas, $17.0 \%$ declared smoking cigarettes during the whole pregnancy $(21.0 \%$ city and $14.0 \%$ countryside $)$ and $14.0 \%$ declared smoking during a part of pregnancy $(12.0 \%$ city and $16.0 \%$ countryside). Among all respondents who smoked before pregnancy, only $2.0 \%$ of them gave up smoking completely during pregnancy. Furthermore, $51.0 \%$ of city residents smoked up to 5 cigarettes a day, $28.0 \% 6-10$ cigarettes a day, and $21.0 \%$ over 10 cigarettes a day. $57.0 \%$ of women living in rural communes smoked up to 5 cigarettes a day, $30.0 \%$ 6-10 cigarettes a day, and $13.0 \%$ over 10 cigarettes a day (34). In our research, every fifth respondent living in the urban areas $(\mathrm{f}=0.21)$ smokes more than 10 cigarettes a day and every fourth respondent from the rural areas $(f=0.24)$ smokes 5 to 10 cigarettes a day, causing harm not only to herself but also to her unborn baby. Every third woman, regardless her place of residence, smoked 3-4 cigarettes a day. Furthermore, almost every fifth city resident $(\mathrm{f}=0.18)$ and every fourth countryside resident ( $\mathrm{f}=0.24$ ) smoked up to 2 cigarettes a day.

Available research data indicate that breastfeeding by women smokers may be a significant source of exposure of babies to toxic substances including tobacco smoke. Exposure of babies to nicotine depends on the daily dose of milk, number of cigarettes smoked a day by the mother, smoking technique, and the time passed from the moment of smoking a cigarette to the moment of breastfeeding (35). It is estimated that in Canada $8-20 \%$ of new-born babies are breastfed by mothers who smoke cigarettes (36). In our study, the percentage of women smoking cigarettes during the breastfeeding period was lower. $4.3 \%$ of respondents living in rural communes and $6.1 \%$ of respondents living in the city smoke or smoked cigarettes during the breastfeeding period, putting the health and life of their children at risk.

To sum up, it should be underlined that motherhood starts as early as during the pregnancy and that it is related to responsibility, which demands elimination of all factors harmful to the baby. Therefore, the analysis of the results of this work and of works by other authors indicate a greater need for education concerning the harmful effects of tobacco smoking before and during pregnancy, and after delivery.

\section{CONCLUSIONS}

The frequency of smoking cigarettes among pregnant women depends on their place of residence. Smoking tobacco in the past was declared more frequently by city residents than countryside residents (58.2\% vs. $41.8 \%)$. On the other hand, active inhalation of tobacco smoke during the month preceding the research was 
admitted more frequently by women living in the rural areas than women living in the urban areas (17.4\% vs. 14.8\%).

It has been observed that the place of residence had an influence on the number of smoked cigarettes among women expecting a baby. Respondents from the city smoked more cigarettes a day than respondents from the countryside (more than 10 cigarettes per day, $f=0.21$ vs. $f=0.16$ ).

Respondents from the rural areas showed more responsibility for the health of their baby and gave up smoking after having their pregnancy confirmed more frequently than respondents from the city did (81.2\% vs. $69.2 \%)$.

A greater care of the health of a new-born baby during the breastfeeding period, by avoiding tobacco smoke, was also observed in respondents from the countryside than those from the city. A smaller percentage of women from the rural areas smoked cigarettes $(4.3 \%)$ and the greater percentage of those women gave up smoking during the breastfeeding period $(43.5 \%)$ as compared to respondents from the urban areas $(6.1 \%$ and $37.5 \%$, respectively).

\section{Conflict of Interests}

None declared

\section{REFERENCES}

1. Kaleta D, Makowiec-Dąbrowska T, Dziankowska-Zaborszczyk E, Fronczak A. Determinants of heavy smoking: results from the global adult tobacco survey in Poland (2009-2010). Int J Occup Med Environ Health. 2012;25(1):66-79.

2. WHO Regional Office for Europe. The current status of the tobacco epidemic in Poland. Copenhagen: WHO Regional Office for Europe; 2009.

3. Zieliński J. The loads resulting from tobacco smoking. Pneumonol Alergol Pol. 2008;76:170-3. (In Polish.)

4. Kowalska A, Stelmach W, Szymański P, Pikala M, Rzeźnicki A. Knowledge about the effects of smoking on health and the developing fetus patients clinic for women in the urban environment and in a small town. Przegl Lek. 2009;66(10):773-6. (In Polish.)

5. Gajewska E, Malak R, Mojs E, Samborski W. Smoking cigarettes - a threat from the first days of life. Przegl Lek. 2008;65(10):709-11. (In Polish.)

6. WHO Regional Office for Europe. Tobacco control base [Internet]. Copenhagen: WHO Regional Office for Europe; 2005 [cited 2017 Dec 1]. Available from: http://data.euro.who.int/tobacco.

7. Billert H, Florek E. Cigarette smoking and other addictions during pregnancy - a problem multidisciplinary. Przegl Lek. 2010;67(10):1048-51. (In Polish.)

8. Kaleta D, Makowiec-Dąbrowska T, Polańska K, Dziankowska-Zaborszczyk E, Drygas W. Smoking and other negative health behaviors among working people. Med Pr. 2009;60(1):7-14. (In Polish.)

9. Samet JM, Yoon SY, editors. Gender, women, and the tobacco epidemic. Geneva: World Health Organization; 2010.

10. Russell T, Crawford M, Woodby L. Measurements for active cigarette smoke exposure in prevalence and cessation studies: why simply asking pregnant women isn't enough. Nicotine Tob Res. 2004;6 Suppl 2:141-51.

11. Brodsky JL, Viner-Brown S, Handler AS. Changes in maternal cigarette smoking among pregnant WIC participants in Rhode Island. Matern Child Health J. 2009;13:822-31.

12. Kalinka J. Evaluation of the role of selected environmental risk factors for fetal growth and preterm birth using biological indicators and biomarkers of exposure. Habilitation thesis. Folia Medica Lodziensia. 2006;33 Suppl 1:1-151. (In Polish.)

13. Szychta W, Skoczylas M, Laudański T. Alcohol consumption and smoking by pregnant women - study review. Perinatol Neonatol Ginekol. 2008;1(4):309-13. (In Polish.)
14. Bodzek P, Bodzek D, Stęplewski Z, Tyrpień K, Urban A, Michalska A. Assessment of the exposure of women to tobacco smoke and its impact on fetal development. Med Pr. 1999;50(5):419-29. (In Polish.)

15. Suzuki K, Ando D, Sato M, Tanaka T, Kondo N, Yamagata Z. The association between maternal smoking during pregnancy and childhood obesity persists to the age of 9-10 years. J Epidemiol. 2009;19(3):136-42.

16. Kaneita Y, Tomofumi S, Suzuki K, Yokoyama E, Miyake T, Harano S, et al. Prevalence of smoking and associated factors among pregnant women in Japan. Prev Med. 2007;45(1):15-20.

17. Fisher N, Amitai Y, Haringman M, Meiraz H, Baram N, Leventhal A. The prevalence of smoking among pregnant and postpartum women in Israel: a national survey and review. Health Policy. 2005;73(1):1-9.

18. Lindqvist R, Lendahls L, Tollbom O, Aberg H, Haksansson A. Smoking during pregnancy: comparison of self-reports and cotinine levels in 496 women. Acta Obstet Gynecol Scand. 2002;81(3):240-4.

19. Grangé G, Vayssière C, Borgne A, Ouazana A, L'Huillier JP, Valensi P, et al. Characteristics of tobacco withdrawal in pregnant women. Eur J Obstet Gynecol Reprod Biol. 2006;125(1):38-43.

20. Torrent M, Sunyer J, Cullinan P, Basagaña X, Harris J, García O, et al. Smoking cessation and associated factors during pregnancy. Gac Sanit. 2004;18(3):184-9.

21. Mohsin M, Bauman AE, Forero R. Socioeconomic correlates and trends in smoking in pregnancy in New South Wales, Australia. J Epidemiol Community Health. 2011;65(8):727-32.

22. Petersen Z, Steyn K, Everett-Murphy K, Emmelin M. Pregnant women's responses to a tailored smoking cessation intervention: turning hopelessness into competence. Glob Health Action. 2010;3: 5379. doi: 10.3402/ gha.v3i0.5379.

23. Connor SK, McIntyre L. The socio-demographic predictors of smoking cessation among pregnant women in Canada. Can J Public Health. 1999;90(5):352-5.

24. Wisborg K, Kesmodel U, Henriksen TB, Olsen SF, Secher NJ. Exposure to tobacco smoke in utero and risk of stillbirth and death in the first year of life. Am J Epidemiol. 2001;154(4):322-7.

25. Chambers CD, Kavteladze L, Joutchenko L, Bakhireva LN, Jones KL. Alcohol consumption patterns among pregnant women in the Moscow region of the Russian Federation. Alcohol. 2006;38:133-7.

26. Lemola S, Grob A. Drinking and smoking in pregnancy: what questions do Swiss physicians ask? Swiss Med Wkly. 2007;137(3/4):66-9.

27. Alves E, Azevedo A, Correia S, Barros H. Long-term maintenance of smoking cessation in pregnancy: an analysis of the birth cohort generation XXI. Nicotine Tob Res. 2013;15(9):1598-607.

28. Ino T. Maternal smoking during pregnancy and offspring obesity: Metaanalysis. Pediatr Int. 2010;52:94-9.

29. Al-Sahab B, Saqib M, Hauser G, Tamin H. Prevalence of smoking during pregnancy and associated risk factors among Canadian women: a national survey. BMC Pregnancy Childbirth. 2010;10:24-32.

30. Ergin I, Hassoy H, Tanik FA, Aslan G. Maternal age, education level and migration: Socioeconomic determinants for smoking during pregnancy in a field study from Turkey. Public Health. 2010;10:325-33.

31. Pirogowicz I, Pomorski M, Jeżowiecka M, Steciwko A. Comparative study of exposure of pregnant women to tobacco smoke: Poland-Mexico. Przegl Lek. 2004;61(10):1020-3. (In Polish.)

32. Borkowski W, Mielniczuk H. Determinants of cigarette smoking and changes in smoking habits in women during pregnancy. Przegl Epidemiol. 2005;59:987-95. (In Polish.)

33. Jagielska I, Kazdepka-Ziemińska A, Racinowski F, Ludwikowski G, Szymański W. The phenomenon of nicotine among pregnant women. Smoking in pregnancy and the condition of the newborn. Przegl Lek. 2007;64(10):618-21. (In Polish.)

34. Łysiak M, Janik A, Wójtowicz B. Cigarette smoking during pregnancy. Zdrow Publiczne. 1993;104(1):21-3. (In Polish.)

35. Florek E, Piekoszewski W. Exposure assessment of fetal, newborn and child to tobacco smoke. Ginekol Prakt. 2002;10(4):10-4. (In Polish.)

36. Lin J, Rosenberg KD, Sandoval AP. Breastfeeding durration and perinatal cigarette smoking in a population - based cohort. Am J Public Health. 2006;96(2):309-14. 